\title{
Pouring of grains onto liquid surfaces: dispersion or lump formation?
}

Xin Yi Ong ${ }^{\dagger}$, Spencer E. Taylor ${ }^{\star}$, Marco Ramaioli ${ }^{\dagger}, *$

${ }^{\dagger}$ Department of Chemical and Process Engineering, University of Surrey, United Kingdom GU2 $7 \mathrm{XH}$.

$\$$ Department of Chemistry, University of Surrey, United Kingdom GU2 7XH

KEYWORDS: Wetting, capillarity, dispersion, grains, lumps 

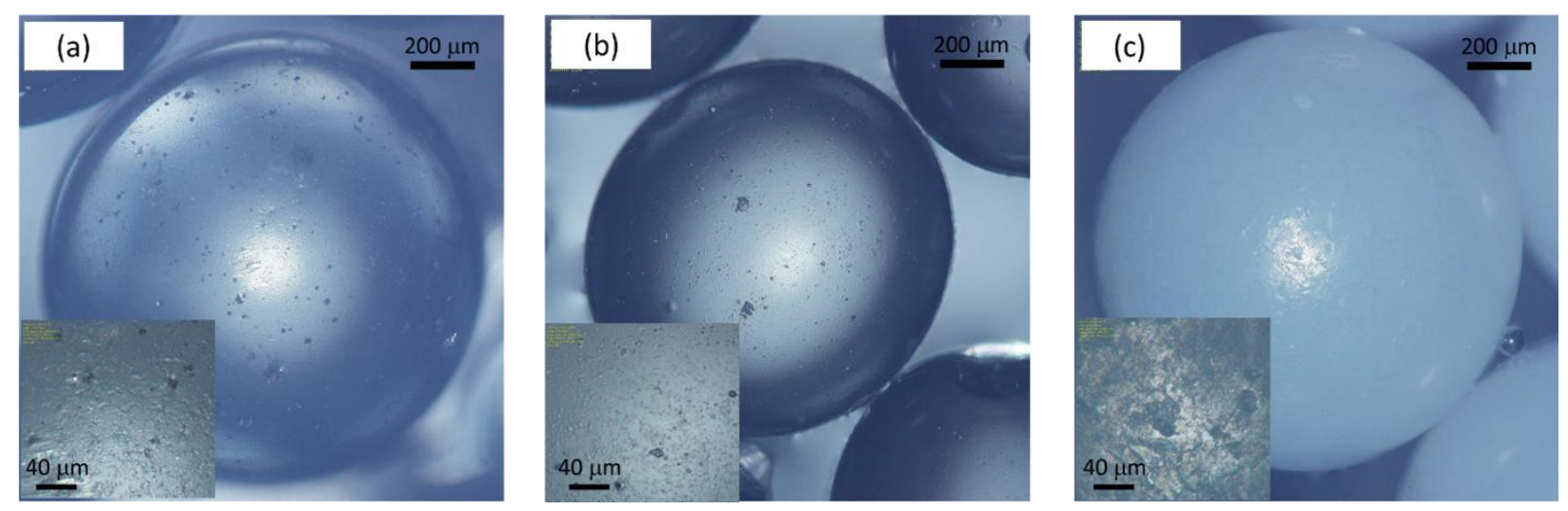

Figure S1. Optical microscopy (bright-field) images showing the typical surfaces of the largest grain size fractions: (a) $1.158 \mathrm{~mm}$ glass; (b) $0.907 \mathrm{~mm}$ PMMA; and (c) $1.152 \mathrm{~mm}$ ZY-S. Each inset image represents the z-profile to a depth of $70 \mu \mathrm{m}$ from each grain surface. The respective scale bars are indicated. 


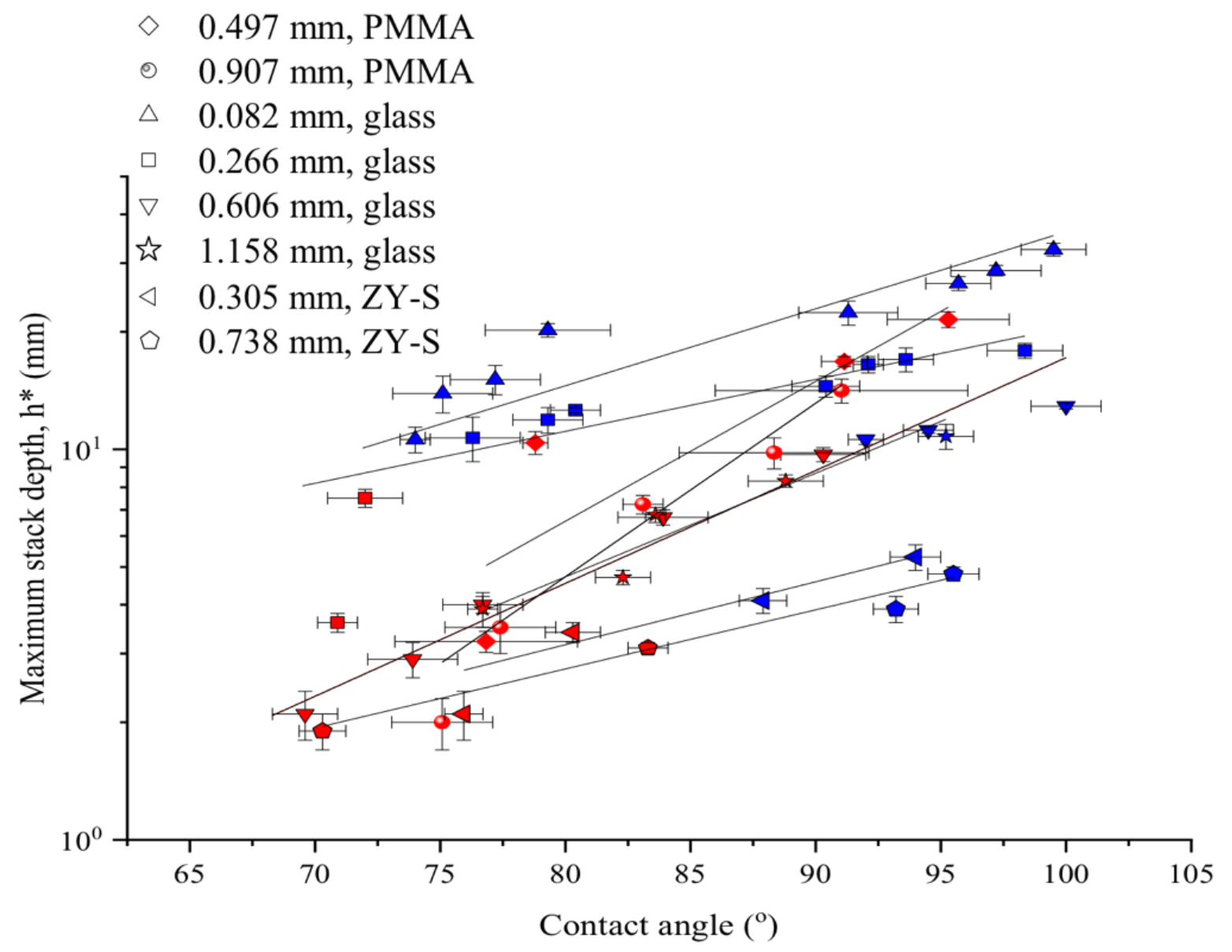

Figure S2. Effect of the contact angle $\theta$ on the maximum depth of a granular stack, $h^{*}$, for grains of different sizes and densities. Blue symbols indicate stacks that detach leading to lump formation and red symbols indicate conditions leading to grain dispersion. The average mass flow rate was $3.8 \pm 1.1 \times 10^{-4} \mathrm{~kg} / \mathrm{s}$. The funnel was located $30 \mathrm{~mm}$ above the liquid surface and using water/ethanol mixtures. The maximum mass of the same stacks is presented in dimensionless form in Figure 5. 


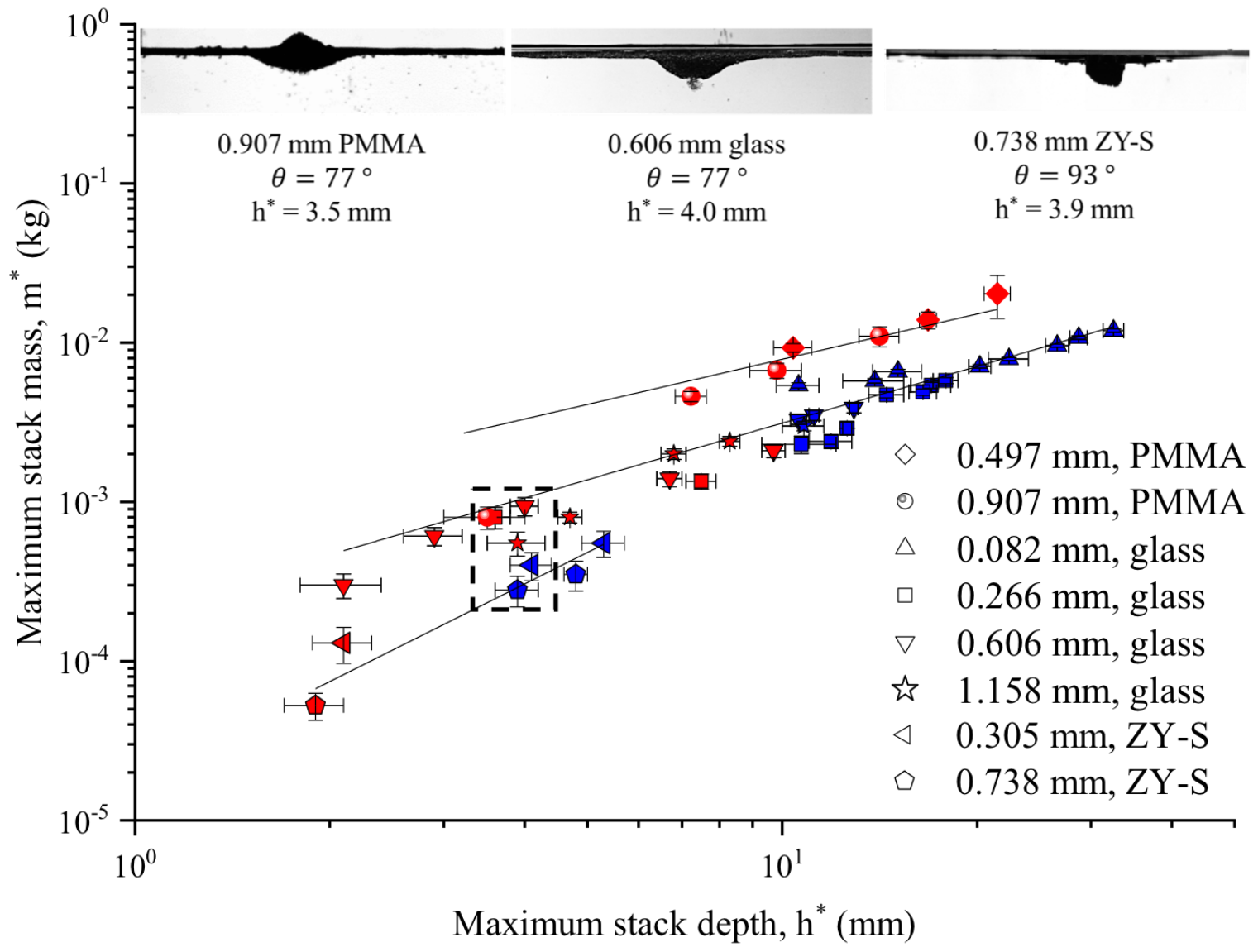

Figure S3. Maximum stack mass, $m^{*}$ as a function of maximum depth of a granular stack, $h^{*}$, for grains of different sizes and densities. Blue symbols indicate stacks that detach with lump formation and red symbols indicate conditions leading to grain dispersion. The inset shows images of stacks with similar $h^{*}$ but formed with grains of different densities. The average mass flow rate was $3.8 \pm 1.1 \times 10^{-4} \mathrm{~kg} / \mathrm{s}$. The funnel was located $30 \mathrm{~mm}$ above the liquid surface and using water/ethanol mixtures. 


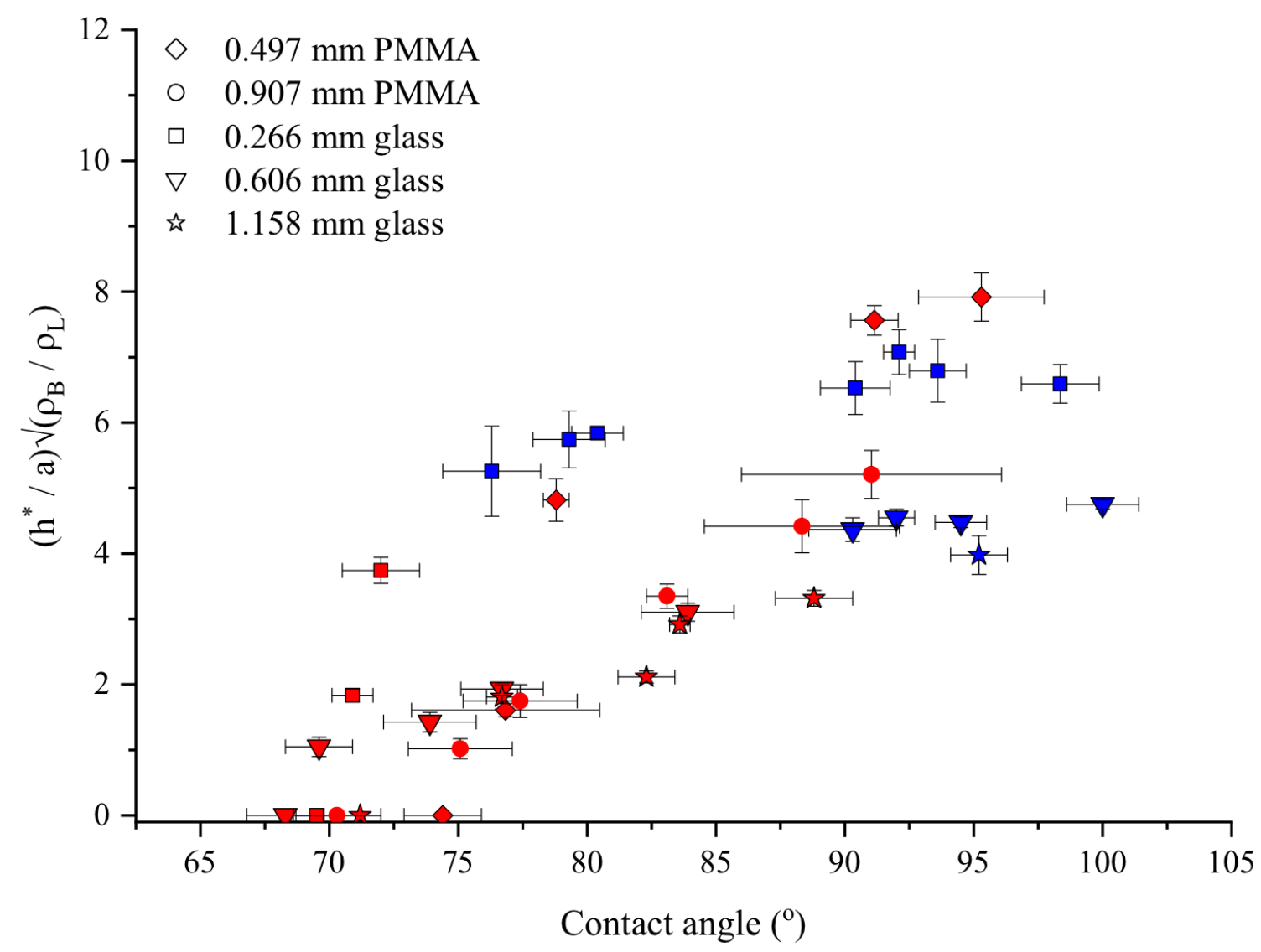

Figure S4. Normalised maximum height of the granular stacks $\left(h^{*} / a\right)\left(\sqrt{\rho_{B} / \rho_{L}}\right)$ as a function of contact angle $\theta$ for PMMA and glass of different grain sizes (indicated on the plot). Blue symbols indicate stacks that detach leading to lump formation and red symbols indicate conditions leading to grain dispersion. The average mass flow rate was $3.8 \pm 1.1 \times 10^{-4} \mathrm{~kg} / \mathrm{s}$. The funnel was located $30 \mathrm{~mm}$ above the liquid surface and using water/ethanol mixtures. 